\title{
Análise histológica da viabilidade do transplante autólogo de hemi-ovário em retroperitônio de ratos $^{1}$
}

\author{
Histological analysis of the viability of half ovary autologous transplantation in \\ retroperitoneal of rats
}

\section{Armando José d'Acampora ${ }^{2}$, Ricardo Tramonte ${ }^{3}$, Fabrício Silva Manoel ${ }^{4}$, Rogério Rodrigues Schmidt ${ }^{5}$, Cyro Trindade Muller ${ }^{6}$, Heitor Tognoli e Silva ${ }^{6}$, Andressa Oliveira $^{6}$, Silvia Dobes Raymundi ${ }^{6}$}
1. Trabalho realizado no Núcleo de Pesquisa de Técnica Operatória e Cirurgia Experimental da Universidade Federal de Santa Catarina (TOCE/UFSC).
2. Professor Adjunto, Doutor em Técnica Operatória e Cirurgia Experimental pela Universidade Federal de São Paulo - Escola Paulista de Medicina (UNIFESP-EPM). Líder do Grupo TOCE/UFSC.
3. Professor Adjunto, Doutor de Histologia do Núcleo de Pesquisa TOCE/UFSC.
4. Médico Residente em Cirurgia Plástica do Hospital de Ipanema, Rio de Janeiro.
5. Médico, Clínico Geral da UFSC.
6. Aluno do Curso de Graduação em Medicina da UFSC.

\section{RESUMO}

OBJETIVO: Analisar a presença de sinais morfológicos indicativos de restabelecimento da função ovariana em hemi-ovários autotransplantados em retroperitônio de ratos Wistar. MÉTODOS: Utilizou-se 48 animais, previamente ooforectomizados bilateralmente. Distribuídos em 6 subgrupos, de acordo com o tempo pós-operatório no qual foram submetidos a retirada das peças a serem histologicamente analisadas, sendo em seguida submetidos a sacrifício. As peças foram fixadas em formol a $10 \%$ por 24 horas, a $4^{\circ} \mathrm{C}$, sendo então incluídas em parafina. Foram obtidos de cada peça 5 cortes semi-seriados de 10 micrômetros de espessura, no sentido transversal do ovário.

RESULTADOS: Os parâmetros morfométricos analisados foram a presença ou ausência de folículos ovarianos, neoformação vascular, corpos lúteos e tecido de granulação. Os resultados das análises demonstraram presença de folículos ovarianos em vários estágios de desenvolvimento, corpos lúteos e neoformação vascular em todos os grupos analisados. Demonstraram também presença de tecido de granulação (infiltrado inflamatório), predominando nos grupos experimentais com menor tempo de pós-operatório.

CONCLUSÃO: Foi possível concluir então que os ovários implantados apresentavam características morfológicas de ovários viáveis, indicando que a implantação permitiu a manutenção dos mesmos no retroperitônio das ratas.

Descritores: Ovário. Histologia. Transplante autólogo. Ratos.

\footnotetext{
ABSTRACT

PURPOSE: To observe the indicative morphological signs of restorable ovarian function in retroperitoneal half-ovaries transplant autologous in Wistar rats.

METHODS: 48 bilaterally oophorectomized female Wistar rats were used. Distributed by 6 groups, according to pos-operative timing, which was done after total removal, from the selftransplanted anatomical region (ovary and psoas muscle) The total ovaries were fixed in formalin during 24 hours, in $4^{\circ}$ Celsius. The morphometric parameters useed in this work
} 
were the presence or absence of ovarian follicles, neovascularization, corpus luteum and granulation tissue.

RESULTS: The results showed presence of ovarian follicles, corpus luteum and neovascularization in all groups. Observation of granulation tissue were more intense visualized in the early groups.

CONCLUSION: The selftransplanted ovaries showed morphological signs of restorable of the ovarian function. Findings suggest that the implantation may allowed a higher survive of them in the retroperitoneum.

Key words : Ovary. Histology. Transplantation, Autologous. Rats.

\section{Introdução}

A síndrome climatérica é considerada prematura, quando ocorre antes da 5. ${ }^{a}$ década de vida. Apresenta incidência entre 3 e $5 \%$ e caracteriza-se por amenorréia secundária hipergonadotrófica ${ }^{7}$, atribuída a múltiplos fatores como desordens genéticas auto-imunes, destruição das células germinativas por infecção viral, drogas, tóxicos ou radiação ionizante, disfunção hipotalâmico/hipofisária, disgenesia gonadal, quimioterapia e ablação ovariana por ooforectomia $^{7,8}$.

A ablação cirúrgica do ovário é realizada em um número significativo de mulheres em idade reprodutiva, acometidas por doenças que devem ser tratadas por tal procedimento, como as neoplasias ovarianas, benignas ou malignas, disgenesia gonadal, endometriose e abscesso tubo-ovariano que não responde à antibioticoterapia. Esta ablação ocorre geralmente como um todo, sem que permaneça no local qualquer segmento glandular que se mostre funcionante $9,10,11$

O hipoestrogenismo decorrente destas situações manifesta-se clinicamente como distúrbio vasomotor representado por fogachos (calorão), alterações tróficas da pele e mucosa genital, com alteração da pilificação vulvar e diminuição do volume dos grandes lábios, diminuição da espessura do epitélio vaginal e da sua lubrificação natural, alterações psicológicas, modificação do perfil lipídico com aumento dos níveis de LDL e triglicerídeos e diminuição dos níveis de HDL, além de aumento da velocidade de perda de massa óssea. Como tratamento, preconiza-se a terapia de reposição hormonal (TRH) ${ }^{3,4,5,6,7}$.

$\mathrm{Na}$ TRH, o estrogênio pode ser reposto pelas vias transdérmica, oral, intravaginal, subcutânea ou intramuscular. A opção da via de administração a ser utilizada é realizada de acordo com o perfil clínico da paciente. A reposição visa aliviar os sintomas vasomotores e psicológicos, prevenir a osteoporose e minimizar as alterações sofridas pelo aparelho cardiovascular na vigência de hipoestrogenismo ${ }^{4,12}$.

Apesar de a TRH já estar estabelecida pela literatura como tratamento para o hipoestrogenismo ${ }^{5,6}$, a opção de transplante ovariano tem sido estudada, ainda em animais de experimentação, como possível via alternativa para a resolução do problema. Ao longo de seu estudo, o transplante ovariano experimental tem sido submetido a várias situações. Ele já foi realizado de forma autóloga e heteróloga, com e sem a preservação de pedículo vascular e implantado em diversas regiões do corpo $13,14,15$.

Os trabalhos até agora presentes na literatura indicam claramente que os ovários transplantados de maneira autóloga em animais experimentais mostram sinais morfológicos de funcionalidade. Tendo sido descritos principalmente a presença de folículos ovarianos, corpos lúteos e de neoformação vascular, encontrados em diferentes períodos de tempo pósoperatório. Os trabalhos que realizaram o transplante de maneira heteróloga indicaram sinais claros de rejeição do tecido ovariano implantado. ${ }^{13,16,17}$. 
A maioria dos trabalhos verificados na literatura pertinente não deixa claro quais os critérios morfológicos e morfométricos utilizados para obtenção dos dados. Torna-se crucial a indicação destes critérios para uma melhor compreensão dos aspectos morfológicos indicativos do restabelecimento da funcionalidade ovariana, que permitam os diversos pesquisadores desta área obter de forma concreta dados histológicos atualizados sobre este tema.

Desta forma o objetivo principal deste trabalho foi analisar e estabelecer os padrões histológicos indicativos da presença de sinais de restabelecimento da função ovariana, em hemi-ovários autotransplantados retroperitonialmente em ratas Wistar.

\section{Métodos}

Foram utilizados 48 Rattus novergicus (Rodentia mammalia), da linhagem Wistar, fêmeas com idade de 60 dias, procedentes do Biotério Central da Universidade Federal de Santa Catarina (U.F.S.C.).

Os animais, submetidos a ooforectomia bilateral, seguida de autotransplante de hemi-ovário direito para retroperitônio, foram distribuídos, aleatoriamente, em seis subgrupos compostos por 8 animais, de acordo com os diferentes tempos pós-operatórios nos quais foram submetidos a sacrifício.

Subgrupo G1 ( $\mathrm{n}=8)$ - realizado o sacrifício no período pós-operatório de 24 horas.

Subgrupo G2 $(\mathrm{n}=8)$ - realizado o sacrifício no período pós-operatório de 72 horas.

Subgrupo G3 $(\mathrm{n}=8)$ - realizado o sacrifício no período pós-operatório de 5 dias.

Subgrupo G4 $(\mathrm{n}=8)$ - realizado o sacrifício no período pós-operatório de 7 dias.

Subgrupo G5 $(\mathrm{n}=8)$ - realizado o sacrifício no período pós-operatório de 14 dias.

Subgrupo G6 $(\mathrm{n}=8)$ - realizado o sacrifício no período pós-operatório de 28 dias.

Os ratos foram submetidos à anestesia geral com éter etílico via inalatória, seguida da administração solução de Cetamina $^{1}$ e Xilasina ${ }^{2}$, nas respectivas doses de $35 \mathrm{mg} / \mathrm{Kg}$ e $5 \mathrm{mg} / \mathrm{Kg}$, por via intramuscular, na face interna da pata traseira esquerda, para manutenção anestésica. O animal foi considerado anestesiado, quando houve perda do reflexo córneopalpebral sem exibir qualquer reação motora à preensão do coxim adiposo de uma de suas patas dianteiras. Os animais foram submetidos à ooforectomia bilateral, seguida de implante de metade do ovário direito em retroperitônio, sobre a fáscia do músculo psoas maior direito, imediatamente abaixo à veia íleo-lombar, realizada através de laparotomia mediana.

No período pós-operatório, foi realizada a observação diária da ferida operatória com relação aos sinais de hemorragia, deiscência e infecção, além de edema em membros posteriores.

Atingido o tempo pós-operatório previsto para realização do sacrifício, os animais foram submetidos novamente ao procedimento anestésico descrito anteriormente, sendo então realizada a retirada em bloco da peça operatória, composta por hemi-ovário e músculo psoas maior direitos, através de ampla incisão abdominal em U invertido. Após a retirada da peça operatória, os animais, ainda anestesiados, eram submetidos a sacrifício por exanguinação.

\section{Estudo histológico}

Cada peça operatória ressecada foi fixada em solução aquosa de formol tamponado ( PBS $0,4 \mathrm{M}$ pH7,4) a $10 \%$ por um período de no mínimo 24 horas em temperatura de 4 graus centígrados mantida com a utilização de um refrigerador.

Estas peças foram submetidas à inclusão em parafina, seguindo a técnica histológica de rotina, obtidos 5 cortes semi-seriados de 10 ? m de espessura de cada uma das peças, no sentido 
transversal do ovário implantado. Os cortes obtidos foram submetidos a coloração pela Hematoxilina-Eosina.

Todos os cortes foram analisados por 2 observadores independentes, sem que os mesmos soubessem a qual grupo experimental pertencia o corte analisado.

A análise das lâminas coradas foi realizada em microscópio óptico convencional, empregando-se oculares dotadas de régua ocular previamente calibrada com lâmina-objeto para cada uma das objetivas de 4 aumentos, 10 aumentos, e 40 aumentos, presentes no microscópio. Desta análise foram obtidos os dados morfométricos em de uma mesma área ( calculada em micrometros quadrados) conhecida para cada um dos grupos experimentais.

Os parâmetros histológicos empregados na análise de todas as laminas foram:

1- Presença ou ausência de tecido de granulação, tanto no ovário como no tecido conjuntivo do músculo psoas maior, em uma área de 100 um, com a objetiva de 4x.

2- Presença ou ausência de folículos ovarianos primários em desenvolvimento com mais de duas camadas de células granulosas, no parênquima do ovário implantado, em uma área de $100 \mathrm{um}$, com a objetiva de 10x.

3- Presença ou ausência de vasos sangüíneos neoformados situados entre o parênquima ovariano e o músculo psoas maior, em uma área de 100 um com a objetiva de 40x.

4- Presença ou ausência de folículos ovarianos primordiais no parênquima ovariano, em uma área de 100 um com a objetiva de 40x.

5- Presença ou ausência de folículos ovarianos secundários (com antro único e sendo visível o ovócito e a camada de células granulares do folículo), em uma área de 100um com a objetiva de 10x.

6- Presença ou ausência de corpo lúteo no parênquima ovariano, em uma área de 100 um com a objetiva de 10x.

Após a obtenção dos dados histológicos em cada um dos grupos de animais analisados, os resultados foram compilados em tabelas comparativas que expressam o percentual de cada um dos parâmetros analisados.

\section{Resultados}

As tabelas abaixo representam os dados numéricos (médias de 5 contagens para cada uma das lâminas coradas pelo H.E) obtidos da análise histológica realizada em 8 ratas de cada um dos diversos grupos experimentais sacrificadas em tempos distintos após a implantação autóloga de hemi-ovário no retroperitônio (Figuras 1 e 2).

TABELA 1 - Número e percentagem de Folículos primordiais, encontrados nos diversos grupos, após o transplante autólogo no retroperitônio de ratos.

\begin{tabular}{l|rrrrrrrrrrrrr}
\hline & \multicolumn{3}{|c}{ G1 } & \multicolumn{1}{c}{ G2 } & \multicolumn{1}{c}{ G3 } & \multicolumn{3}{c}{ G4 } & \multicolumn{3}{c}{ G5 } & \multicolumn{2}{c}{ G6 } \\
& $\mathrm{n}$ & $\%$ & $\mathrm{n}$ & $\%$ & $\mathrm{n}$ & $\%$ & $\mathrm{n}$ & $\%$ & $\mathrm{n}$ & $\%$ & $\mathrm{n}$ & $\%$ \\
\hline Presença & 0 & 0 & 4 & 50 & 0 & & 0 & 4 & 50 & 5 & 75 & 3 & 37,5 \\
Ausência & 8 & 100 & 4 & 50 & 8 & 100 & 4 & 50 & 2 & 25 & 5 & 62,5 \\
& & & & & & & & & & & & & \\
\hline TOTAL & 8 & 100 & 8 & 100 & 8 & 100 & 8 & 100 & 8 & 100 & 8 & 100 \\
\hline
\end{tabular}


TABELA 2 - Número e percentagem de Folículos primários em desenvolvimento, encontrados nos diversos grupos, após o transplante autólogo no retroperitônio de ratos.

\begin{tabular}{rrrrrrrrrrrrr}
\hline & \multicolumn{2}{c}{ G1 } & \multicolumn{2}{c}{ G2 } & \multicolumn{2}{c}{ G3 } & \multicolumn{2}{c}{ G4 } & \multicolumn{2}{c}{ G5 } & \multicolumn{2}{c}{ G6 } \\
\hline & $\mathrm{n}$ & $\%$ & $\mathrm{n}$ & $\%$ & $\mathrm{n}$ & $\%$ & $\mathrm{n}$ & $\%$ & $\mathrm{n}$ & $\%$ & $\mathrm{n}$ & $\%$ \\
\hline Presença & 4 & 50 & 7 & 87,5 & 3 & 37,5 & 5 & 62,5 & 5 & 62,5 & 8 & 100 \\
& & & & & & & & & & & & \\
\hline Ausência & 4 & 50 & 1 & 12,5 & 5 & 62,5 & 3 & 37,5 & 3 & 37,5 & 0 & 0 \\
& & & & & & & & & & & & \\
\hline TOTAL & 8 & 100 & 8 & 100 & 8 & 100 & 8 & 100 & 8 & 100 & 8 & 100 \\
\hline
\end{tabular}

TABELA 3 - Número e percentagem de Folículos secundários com um único antro folicular, encontrados nos diversos grupos, após o transplante autólogo no retroperitônio de ratos.

\begin{tabular}{lrrrrrrrrrrrrr}
\hline & \multicolumn{3}{c}{ G1 } & \multicolumn{1}{c}{ G2 } & \multicolumn{3}{c}{ G3 } & \multicolumn{3}{c}{ G4 } & \multicolumn{2}{c}{ G5 } & \multicolumn{2}{c}{ G6 } \\
& $\mathrm{n}$ & $\%$ & $\mathrm{n}$ & $\%$ & $\mathrm{n}$ & $\%$ & $\mathrm{n}$ & $\%$ & $\mathrm{n}$ & $\%$ & $\mathrm{n}$ & $\%$ \\
\hline Presença & 0 & 0 & 0 & 0 & 0 & & 0 & 3 & 37,5 & 6 & 75 & 7 & 87,5 \\
& & & & & & & & & & & & \\
Ausência & 8 & 100 & 8 & 100 & 8 & 100 & 5 & 62,5 & 2 & 25 & 1 & 12,5 \\
& & & & & & & & & & & & \\
\hline TOTAL & 8 & 100 & 8 & 100 & 8 & 100 & 8 & 100 & 8 & 100 & 8 & 100 \\
\hline
\end{tabular}

TABELA 4 - Número e percentagem de corpo lúteo, encontrados nos diversos grupo , após o transplante autólogo no retroperitônio de ratos.

\begin{tabular}{|c|c|c|c|c|c|c|c|c|c|c|c|c|}
\hline & \multicolumn{2}{|c|}{ G1 } & \multicolumn{2}{|c|}{ G2 } & \multicolumn{2}{|c|}{ G3 } & \multicolumn{2}{|c|}{ G4 } & \multicolumn{2}{|c|}{ G5 } & \multicolumn{2}{|c|}{ G6 } \\
\hline & $\mathrm{n}$ & $\%$ & $\mathrm{n}$ & $\%$ & $\mathrm{n}$ & $\%$ & $\mathrm{n}$ & $\%$ & $\mathrm{n}$ & $\%$ & $\mathrm{n}$ & $\%$ \\
\hline Presença & 1 & 12,5 & 5 & 62,5 & 1 & 12,5 & 5 & 62,5 & 8 & 100 & 8 & 100 \\
\hline Ausência & 7 & 87,5 & 3 & 37,5 & 7 & 87,5 & 3 & 37,5 & 0 & 0 & 0 & 0 \\
\hline TOTAL & 8 & 100 & 8 & 100 & 8 & 100 & 8 & 100 & 8 & 100 & 8 & 100 \\
\hline
\end{tabular}

TABELA 5 - Comparação entre o número médio de folículos secundários e primários em desenvolvimento encontrados nos cortes histológicos obtidos de ovários autotransplantados no retroperitônio de ratos.

\begin{tabular}{lcccccc}
\hline & G1 & G2 & G3 & G4 & G5 & G6 \\
\hline $\begin{array}{l}\text { Primar. em } \\
\text { desenvolvimento }\end{array}$ & 7,75 & 3,5 & 2,5 & 3,9 & 2,8 & 2 \\
\hline Secund. & 0 & 0 & 0 & 1,33 & 2 & 1,75 \\
\hline
\end{tabular}


TABELA 6 - Número médio de vasos neoformados, em uma área de tecido de 100 um junto ao ovário autotransplanta no retroperitônio de ratos por grupo experimental analisado.

\begin{tabular}{l|cccccc}
\hline & G1 & G2 & G3 & G4 & G5 & G6 \\
\hline $\begin{array}{l}\text { Número } \\
\text { médio }\end{array}$ & 3,66 & 5,4 & 2,6 & 8,5 & $>10$ & 8,5 \\
\hline
\end{tabular}

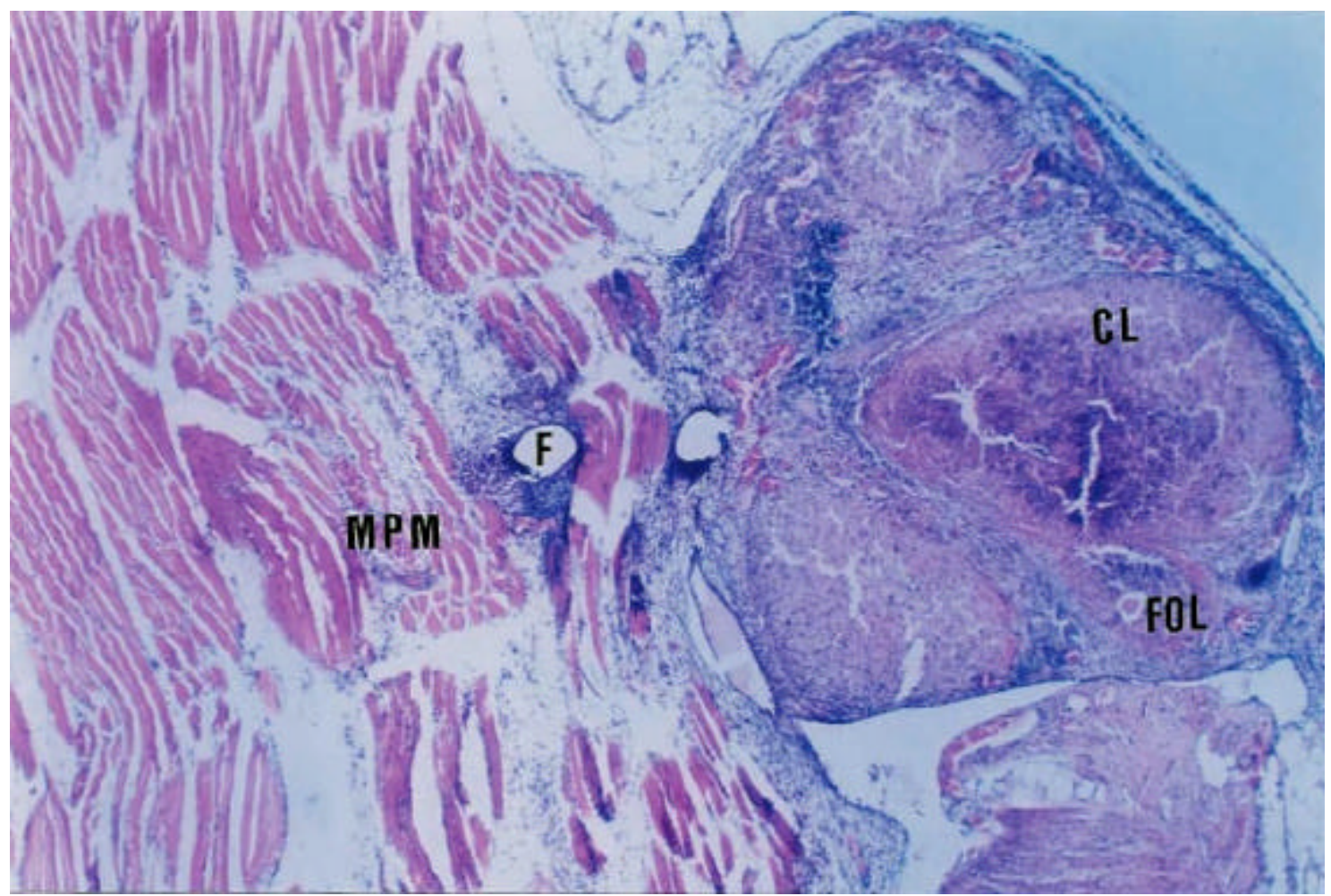

FIGURA 1 - Fotomicrografia de um corte histológico de ovário (Coloração HE) Implantado no músculo psoas maior (MPM), indicando a posição do fio de sutura (F) em uma secção Transversal realizada na peça histológica. Nota-se a presença de corpo lúteo (CL) e folículos em desenvolvimento(FOL) na peça implantada. Animal do Grupo A2 (Objetiva 4 aumentos) 


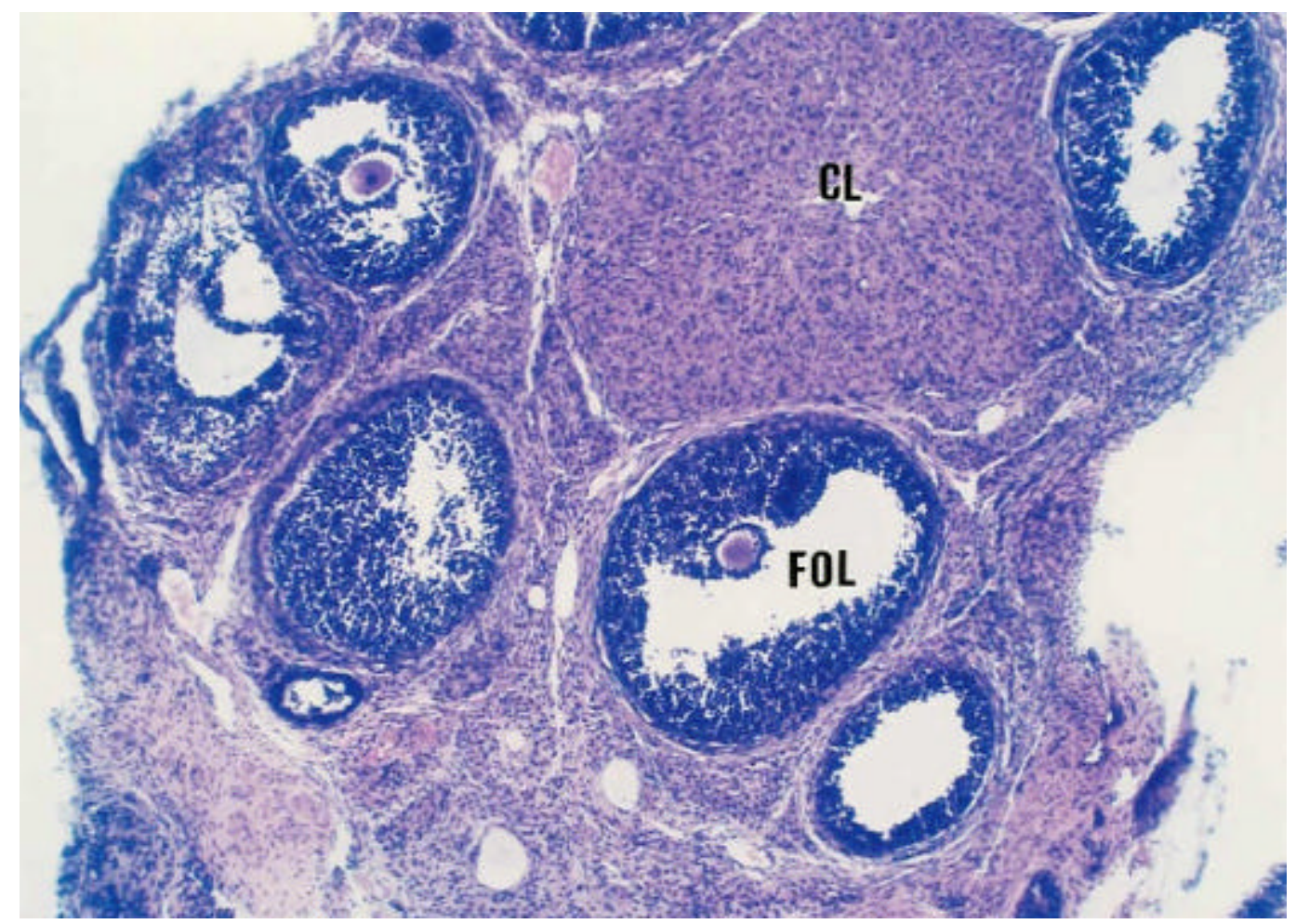

FIGURA 2 - Fotomicrografia de um corte histológico de ovário implantado em animal do Grupo A4, indicando a presença de folículos (FOL) ovarianos em pleno desenvolvimento com ovócito viável e presença de corpo lúteo (CL). (Objetiva de 10 aumentos, coloração HE)

\section{Discussão}

Nos estudos realizados sobre autotransplante ovariano, o rato é o animal mais utilizado para comparação de resultados morfológicos e por este fato, foi o animal escolhido para a realização do presente trabalho. Apresenta ciclo ovariano reduzido, completando-se em torno de 4 ou 5 dias, ideal para estudar a recuperação da função ovariana, em um período curto de avaliação pós-operatória ${ }^{18}$. Além disso, o mesmo apresenta-se também como animal de fácil manuseio e obtenção.

Optou-se pela técnica de autotransplante ovariano sem utilização de pedículo vascular, técnica realizada com sucesso, conforme demonstrado pela literatura $13,14,15,16,17,20$.

Utilizou-se 1/2 de um ovário para o autotransplante, baseando-nos no trabalho de Corleta HE, Corleta O, Capp E, Edelweiss MI. ${ }^{13}$, que comparou os resultados obtidos entre o autotransplante de ovários inteiros e fragmentados, e concluiu que a utilização de fragmentos ovarianos garante maior taxa de viabilidade ovariana, fato também observado neste estudo.

Os folículos ovarianos (aqui considerados, em conjunto, os folículos primários, em desenvolvimento e maduros) foram visualizados a partir de 24 horas de pós-operatório, em 50 $\%$ dos ovários autotransplantados. Isto indicou que a nutrição do tecido ovariano, provavelmente por embebição, foi eficaz, impedindo que houvesse degeneração de suas células funcionais nas primeiras 24 horas após o transplante.

Com 72 horas de pós-operatório, o número de ovários nos quais foram visualizados folículos subiu para 87,5\%, confirmando a manutenção eficaz da nutrição ovariana, sugerida com 24 horas.

Entretanto, no $5^{\circ}$ dia de pós-operatório os folículos só foram visualizados em 37,5\% dos ovários autotransplantados, refletindo diminuição da função ovariana. Este dado sugere que 
houve algum grau de sofrimento do tecido neste período, provavelmente decorrente do processo inflamatório intenso demonstrado em todas as peças com 72 horas de evolução.

No $7^{\circ}$ dia pós-operatório houve recuperação da produção folicular. Esta foi demonstrada pela visualização de folículos em $87,5 \%$ dos ovários autotransplantados.

Esta recuperação manteve-se no $14^{\circ}$ dia de pós-operatório, sugerindo manutenção de uma produção folicular constante, provavelmente por estabilização da nutrição ovariana, garantida pela neovascularização estabelecida enxerto e hospedeiro. Com 14 dias de pós-operatório os folículos foram visualizados em $75 \%$ dos ovários.

Com 28 dias de pós-operatório os folículos foram visualisados em todos os ovários, levando a concluir que neste período pós-operatório o ovário se mantinha viável, sendo provavelmente nutrido pela neovascularização que se desenvolveu entre o sítio de enxertia e a gônada autotransplantada.

O corpo lúteo é uma estrutura composta por células teco-luteínicas e granuloso-luteínicas provenientes do folículo ovariano roto, que sofre transformação após o fenômeno da ovulação. Constitui, portanto, sinal direto da ocorrência de ovulação ${ }^{1,2}$.

No presente trabalho, corpos lúteos puderam ser observados com 24 horas de pós-operatório em $12,5 \%$ dos ovários. Isto indica que houve ovulação prévia a exérese e autotransplante do mesmo, assim como manutenção da nutrição ovariana, demonstrada pela preservação dos corpos lúteos no primeiro dia pós-operatório.

Com 72 horas de evolução, foram visualizados corpos lúteos em 62,5\% dos ovários transplantados. Levando a crer que ocorreu desenvolvimento dos folículos ovarianos presentes com 24 horas de evolução, culminando em ovulação dos mesmos, com conseqüente formação dos corpos lúteos neste período pós-operatório.

Aos 5 dias de evolução, os corpos lúteos foram visualizados em menor porcentagem, apenas em 12,5\% dos ovários autotransplantados. Este dado reforça a hipótese de haver sofrimento vascular entre 72 horas e 5 dias de pós-operatório, já sugerido anteriormente pelos dados discutidos a respeito do comportamento pós-operatório dos folículos ovarianos.

A partir do $7^{\circ}$ dia pós-operatório, os corpos lúteos foram visualizados em $62,5 \%$ dos ovários autotransplantados. No $14^{\circ}$ e no $28^{\circ}$ dia, foram visualizados em todos eles. Este dado vem reforçar a suposição de que a partir do $7^{\circ}$ dia de evolução há estabilização da nutrição ovariana, com manutenção de sua função.

A inflamação é uma reação orgânica à lesão tecidual. Tem como objetivo final o reparo do dano ocorrido. Suas reações levam à formação de um tecido conectivo, rico em neovasos, chamado tecido de granulação. Este tem como função revitalizar, se possível o tecido lesado, e recuperar a integridade do mesmo, a partir da deposição de colágeno ${ }^{21}$.

Nos ovários, autotransplantados, o tecido de granulação foi visualizado com 24 horas de pósoperatório apenas no tecido ovariano, em $75 \%$ dos ovários.

A partir de 72 horas, o tecido de granulação já pôde ser visualizado no tecido ovariano autotransplantado e no tecido muscular (sítio receptor do enxerto) em todas as peças, demonstrando reação inflamatória importante envolvendo os dois tecidos.

A partir do $5^{\circ}$ dia, a reação inflamatória continuava sendo visualizada nos dois tecidos (ovariano e muscular), porém não em todas as peças (em 87,5 \% dos ovários e em $75 \%$ dos músculos).

No $7^{\circ}$ dia, ela manteve-se estável no tecido ovariano $(87,5 \%)$, e continuou visível no tecido muscular, porém em um menor número de peças $(50 \%)$.

No $14^{\circ}$ dia, o tecido de granulação continuava visível em ovários e tecido muscular, com pequena diminuição da porcentagem de ovários nos quais se fazia presente $(75 \%)$., revelando reagudização da reação inflamatória, na gônada autotransplantada. No tecido muscular, houve diminuição do número de peças nas quais foi visualizada a reação inflamatória $(25 \%)$. Isto 
demonstrou a diminuição da reação inflamatória ao nível de tecidos autotransplantado e receptor.

A presença de vasos neoformados foi visualizada em todos os períodos pós-operatórios estudados, demonstrando a precocidade de início da revascularização, compatível com as reações inflamatórias demonstradas pelo estudo do tecido de granulação no presente trabalho. A neoangiogênese apresentou-se com 24 horas de evolução em $75 \%$ dos ovários autotransplantados, com número médio de 3,66 vasos em cada gônada.

Com 72 horas de pós-operatório, a neovascularização se fazia presente já em 87,5 \% dos ovários, com número médio de 5,4 vasos. Demonstrando progressão da neovascularização.

No $5^{\circ}$ dia, houve uma pequena queda da porcentagem de ovários com neovascularização (75 $\%)$, assim como no número médio de vasos $(2,6)$. Fato que provavelmente explica a queda na porcentagem de folículos ovarianos e corpos lúteos neste período pós-operatório.

No $7^{\circ}$ dia de pós-operatório, a porcentagem de ovários com neovascularização era de 87,5\% No $14^{\circ}$ e no $28^{\circ}$ dia era de $100 \%$. Com números médios de vasos de 8,5 aos 7 dias e superior a 10 aos 14 dias e novamente 8,5 aos 28 dias. Estes dados confirmam a progressão da neovascularização e provavelmente explicam a obtenção de viabilidade ovariana, descrito pelo presente trabalho.

Confrontando nossos resultados com os dados presentes na literatura, pudemos observar que a nossa taxa de presença de folículos após 28 dias (100\%) foi superior àquelas relatadas por Harris e Eakin ${ }^{10}$ em 1949 (90,1\%) após 30 dias de pós-operatório, por R, Leibach J, Black J, Keldahl C, Karow A. ${ }^{14}$, em 1982 (75\%) após 45 dias de pós-operatório e por Corleta e col ${ }^{13}$. em $1998(88,8 \%)$ após 21 dias de pós-operatório.

Harris e Eakin ${ }^{10}$ demonstraram também taxa de presença de corpos lúteos de 90,1 \% após 30 dias de pós-operatório. Nossa taxa, com 28 dias, revelou-se superior, com presença de corpos lúteos em todas as peças. Quattropani ${ }^{11}$ demonstrou taxa de aparecimento de corpos lúteos após 14 dias de pós-operatório de $30 \%$, valor muito inferior àquele encontrado por nós neste mesmo período pós-operatório (100\%).

A presença de neovascularização foi demonstrada por nosso estudo já com 24 horas de pósoperatório. Este dado é condizente com os dados descritos por Harris e Eakin ${ }^{10}$, em 1949, e por Corleta ${ }^{13}$, em 1998, que relataram presença de conexão vascular entre auto-enxerto e hospedeiro com 72 horas de pós-operatório. Dissen GA, Lara HE, Fahrenbach WH, Costa ME, Ojeda SR. ${ }^{16}$, em 1994, relatou a presença de vasos neoformados com 48 horas de pósoperatório.

Por meio dos dados obtidos em nosso trabalho é possível concluir que houve preservação da viabilidade ovariana, pela presença de folículos ovarianos, neovascularização e corpos lúteos. Isto está de acordo com a descrição da maioria dos autores que utilizaram técnica de transplante ovariano semelhante a nossa ${ }^{13,14,16,17}$.

\section{Conclusão}

Os ovários implantados apresentam características morfológicas de ovários viáveis, com a presença de folículos ovarianos, corpos lúteos e neoformação vascular. Isto indica que a implantação permitiu a manutenção dos mesmos retroperitonealmente.

\section{Referências}

1. Hurd W. Menopausa. In: Berek JS, Adashi EY, Hillard PA. Novak - Tratado de Ginecologia. $12^{\mathrm{a}}$ ed. Rio de Janeiro: Guanabara Koogan; 1998, 696-716.

2. Davis AJ. Cirurgia dos anexos. In: Gershenson DM, Decherney AH, Currey SL. Ginecologia operatória. $1^{\mathrm{a}}$ ed. Rio de Janeiro: Guanabara Koogan; 1995, 441-8.

3. Salum R. Doenças benignas dos ovários. In: Halbe HW. 2ed. São Paulo: Rocca; 1993. p.1103-16. 
4. Bagnoli VR, Hayashida SA. Estados intersexuais . In: Halbe HW. 2ed. São Paulo: Rocca; 1993. p.1340-66.

5. Görgens JB, Ferreira CR, Oliveira LC. Hormonioterapia de reposição em climatério. J Bras Ginecol 1992,102: 381-5.

6. Mendonça M, Trindade CR, Guimarães DA, Oliveira FA. Hipoestrogenismo: diagnóstico e tratamento. J Bras Ginecol 1995,105: 371-4.

7. Fonseca AM, Halbe HW. Fisiologia do climatério. São Paulo: Rocca; 1993.

8. Fonseca AM, Halbe HW. Síndrome do climatério. São Paulo: Rocca; 1993.

9. Paiva LH, Pinto-Neto AM, Bedone AJ, D’assumpção LV, Luiz FA, Lúcio MA. Falência ovariana precoce: relato de 23 casos. J Bras Ginecol 1992,102: 259-63.

10. Harris M, Eakin RM. Survival of transplanted ovaries in rats. J Exp Zool 1949;112:131-64.

11. Quattropani SL. Ovulation of ovarian implants in unilaterally ovariectomized rats. Anat Rec 1984;209:3316.

12. Green CJ, Simpkin S, Grimaldi G, Johnson A. Pregnancy after autografting and allografting vascularized ovaries and en bloc vascularized ovaries with adnexa in rabbits. Br J Obstet Gynaecol 1982;89:645-51.

13. Corleta HE, Corleta O, Capp E, Edelweiss MI. Subcutaneous autologous ovarian transplantation in Wistar rats maintains hormone secretion. Fertil Steril 1998; 70(1):16-9.

14. Harp R, Leibach J, Black J, Keldahl C, Karow A. Cryopreservation of murine ovarian tissue. Cryobiology 1994,31:336-43.

15. Freeman ME. The neuroendocrine control of the ovarian cycle of the rat. 2ed. New York: Raven; 1994.

16. Dissen GA, Lara HE, Fahrenbach WH, Costa ME, Ojeda SR. Imature rat ovaries become revascularized rapidly after autotransplantation and show a gonadotropin-dependent increase in angiogenic factor gene expression. Endocrinology 1994;134(3):1146-54.

17. Manoel FS, Tramonte R, Schimdt RR, Muller CT, Tognoli T, Oliveira A, Raymundi SD, d'Acampora AJ. Análise histológica da viabilidade de transplante ovariano para o retroperitônio de ratas. Acta Cir Bras 2001;17(suppl.1):77.

18. Guyton AC, Hall JE. Tratado de fisiologia médica. 9ed. Rio de Janeiro: Guanabara Koogan; 1997.

19. Mamede MV, Souza L, Rodrigues RP, Shimo AK, Almeida AM, Ravagnani MC, Silva RM. Menarcamenopausa: quando ocorrem? J Bras Ginecol 1992;102:441-4.

20. Robbins SL, Cotran RS, Kumar V, Shoen FJ. Patologia estrutural e funcional. 5ed. Rio de Janeiro: Guanabara Koogan; 1996.

Correspondência:

Armando José d'Acampora

Condomínio San Diego, casa 9

88034-420 Florianópolis - SC

acampora@ccs.ufsc.br

Recebimento: 25/03/2004

Revisão: 02/05/2004

Aprovação: 18/06/2004

Conflito de interesse: nenhum

Fonte de financiamento: nenhuma

\section{Como citar este artigo:}

d'Acampora AJ, Tramonte R, Manoel FS, Schmidt RR, Muller CT, Silva HT, Oliveira A, Raymundi SD. Análise histológica da viabilidade do transplante autólogo de hemi-ovário em retroperitônio de ratos. Acta Cir Bras [serial online] 2004 Jul-Ag;19(4). Disponível em URL: http://www.scielo.br/acb [também em CD-ROM]. 